\title{
EGFR and K-Ras mutations in women with lung adenocarcinoma: implications for treatment strategy definition
}

Virginia Rotella ${ }^{1}$, Lorenzo Fornaro ${ }^{1}$, Enrico Vasile ${ }^{2}$, Carmelo Tibaldi ${ }^{3}$, Laura Boldrini ${ }^{4}$, Antonio Chella ${ }^{5}$, Armida D'Incecco ${ }^{3}$, Giovanna Cirigliano ${ }^{1}$, Aldo Chioni ${ }^{6}$, Cristiana Lupi ${ }^{7}$, Elisa Sensi ${ }^{7}$, Laura Ginocchi ${ }^{2}$, Simona Giovannelli ${ }^{1}$, Maria Cristina Pennucci ${ }^{8}$, Gabriella Fontanini ${ }^{4}$ and Editta Baldini ${ }^{{ }^{*}}$

\begin{abstract}
Background: We aimed at investigating the outcomes of female patients with stage IIIB-IV adenocarcinoma of the lung according to EGFR and K-Ras mutational status.

Methods: One hundred and three consecutive female patients genotyped at a single Italian Institution were analyzed. Patients were planned to receive first-line platinum-based chemotherapy (CT) and a salvage treatment with anti-EGFR tyrosine-kinase inhibitors (TKIs) was proposed irrespective of tumor mutational status. EGFR (exons 18-21) and K-Ras (exon 2, codons 12-13) mutations were evaluated by real-time PCR and pyrosequencing. The association of mutational status with clinical variables and treatment benefit was investigated by chi-square test and log-rank test.

Results: EGFR and K-Ras mutations were found in 31 (30\%) and 13 (15\%) cases, respectively. Sixty-six patients received platinum CT: no correlation was observed between EGFR or K-Ras mutational status and response rate (RR) $(p>0.05)$. However, patients treated with first-line $C T$ harboring EGFR activating mutations experienced a significantly reduced progression-free survival (PFS) in comparison with wild-type ones (4.4 vs. 6.4 months, respectively; HR 0.597, $95 \% \mathrm{Cl} 0.287-0.975 ; \mathrm{p}=0.048$ ). Thirty-nine patients received salvage treatment with erlotinib: EGFR activating mutations were significantly correlated with RR (60\% vs. 12.5\%; $p=0.004$ ) and PFS (11.4 vs. 4.5 months; HR $0.491,95 \% \mathrm{Cl} 0.216-0.936$; $p=0.044)$. Responses to erlotinib were not reported among women with K-Ras mutant tumors, while $50 \%$ of those with wild-type K-Ras achieved an objective remission ( $p=0.296$ ). Median PFS (3.5 vs. 8.8 months; HR 0.284, 95\% Cl 0.015-0.510; $p=0.010$ ) and OS (3.9 vs. 19.8 months; HR 0.158, 95\% Cl 0.001-0.075; $p<0.001$ ) were significantly shorter among K-Ras mutant patients treated with TKI.
\end{abstract}

Conclusions: In our population of Caucasian women with advanced lung adenocarcinoma we observed that the presence of EGFR activating mutations correlates with a significant reduction in the benefit from first-line platinum-based $\mathrm{CT}$, emphasizing the importance of an upfront use of anti-EGFR TKIs in this patient subset. K-Ras mutations seem to correlate with a detrimental effect from anti-EGFR TKI, but this finding deserves further investigation.

Keywords: Lung adenocarcinoma, EGFR, K-Ras, Chemotherapy, Tyrosine-kinase inhibitors

\footnotetext{
* Correspondence: e.baldini@usl2.toscana.it

'U.O. Oncologia Medica, Ospedale San Luca, Lucca, Italy

Full list of author information is available at the end of the article
} 


\section{Background}

The epidermal growth factor receptor (EGFR) and K-Ras are among the most investigated molecular drivers in solid tumors. In particular, EGFR is addressed as an interesting target for several biologic agents, mainly monoclonal antibodies (acting at the cellular surface level) and small molecules (inhibiting the intracellular tyrosine-kinase domain activity) [1]. EGFR overexpression often correlates with a worse prognosis is several tumors [2] and the blockade of the EGFR-driven cascade has been proved successful in non-small cell lung cancer (NSCLC), colorectal, head and neck and breast cancer [1]. Mutations in K-Ras, occurring at different levels along the gene sequence, have been described in multiple malignancies [3]. Moreover, K-Ras has been the first predictive biomarker identified and routinely used in advanced colorectal cancer management: mutations in this key oncogene predict the benefit from the anti-EGFR monoclonal antibodies panitumumab and cetuximab [4], and the role of mutations in different Ras family members (such as N-Ras) is rapidly emerging as an essential tool for patient selection in this disease [5].

NSCLC in women is a growing health concern in Western countries [6]. Gender-related factors (modulating smoking-dependent and independent carcinogenesis) may contribute to this increased incidence [7]. The disease is reported as a peculiar pathological and molecular entity: in particular, women are more often affected by lung adenocarcinoma and the tumor arises among never- or light-smokers with higher frequency than in men [7].

Following the observation that female gender was one of the clinical features associated with a benefit from anti-EGFR tyrosine-kinase inhibitors (TKIs) (together with Asian origin, adenocarcinoma histology and smoking habits) [8,9], deeper insights into the EGFR biology allowed to identify somatic mutations in the kinase domain of the EGFR gene [10]. Nowadays, EGFR mutational status is a well-recognized predictive factor for anti-EGFR TKIs activity and an essential tool for treatment allocation in advanced lung adenocarcinoma [11].

However, the impact of first-line platinum-based chemotherapy $(\mathrm{CT})$ in female patients with EGFR mutated adenocarcinoma is a matter of debate and no definitive data emerge from subgroup analyses of randomized trials comparing CT with TKIs in the first-line setting [8]. The results of a recent meta-analysis of prospective and retrospective studies suggest that EGFR mutations may be associated with higher response rate (RR) to CT, but may not predict the benefit of CT with regard to progression-free survival (PFS) and overall survival (OS) [12].

Among the other molecular aberrations involved in NSCLC progression, K-Ras is certainly one of the most extensively studied [13]: K-Ras mutations (mainly located in codons 12 and 13 of exon 2) are reported in up to $30 \%$ of NSCLC cases $[13,14]$, especially among smokers. It is worth noting that EGFR and K-Ras mutations are rarely found in the same tumor, suggesting that they may drive functionally different carcinogenetic processes [13,14]. Direct targeting of K-Ras has recently raised some concerns, as this represents a key transduction pathway in both normal and tumor tissues. Moreover, several parallel escape mechanisms have been identified [15]. Moving from these considerations, alternative targeting of K-Ras is currently under evaluation, e.g. by inhibiting BRAF or MEK activity [15].

Inconclusive evidence exists about the role of K-Ras mutations in predicting the benefit of $\mathrm{CT}$ in lung adenocarcinoma [16]. On the other hand, retrospective subgroup analyses seem to suggest that patients with K-Ras mutated tumors show a primary resistance to anti-EGFR TKIs [14]. Two meta-analyses demonstrated that the objective RR to anti-EGFR TKIs in K-Ras mutated tumors is inferior to wild-type ones $[17,18]$. However, no definitive conclusion was reported in terms of PFS and OS.

In our clinically enriched series (Caucasian women with lung adenocarcinoma) we aimed at investigating the possible predictive significance of EGFR and K-Ras mutations with respect to both first-line platinum-based CT and salvage treatment with the anti-EGFR TKI erlotinib.

\section{Methods \\ Eligibility criteria}

We retrospectively identified consecutive women with histologically or cytologically confirmed stage IIIB-IV adenocarcinoma of the lung treated at five Italian Institutions between 2007 and 2010. All patients had their tumor samples available for centralized molecular determinations and were included in the descriptive analyses of mutation frequency. Patients who had received any first-line platinum-based combination regimen for advanced disease and had undergone tumor evaluations were included in the correlative analyses for response and survival.

Pre-treatment evaluation included: clinical history, physical examination, complete blood cell count and biochemistry, computed tomography scan of the chest and computed tomography scan or ultrasonography of the abdomen. Patients with central nervous system (CNS) metastases were considered eligible if they were asymptomatic or stable at imaging evaluation performed 1 month after the completion of brain radiotherapy.

\section{Treatment}

Any platinum-containing regimen was allowed as upfront therapy: CT was administered for a maximum of 6 courses in responding patients and no maintenance treatment was administered. Salvage treatment with erlotinib $150 \mathrm{mg} /$ die orally was given on the basis of clinician's choice according to initial marketing indications of this 
drug: this strategy was not pre-planned. The choice between erlotinib and CT was driven by clinical factors (i.e. performance status, organ function, life expectancy, tolerance and response to previous CT). Best supportive care alone was offered to patients with reduced life expectancy $(<4$ weeks), compromised liver, kidney or bone marrow function, and deteriorated performance status.

Anti-EGFR TKI treatment was administered until progression, unacceptable toxicity or patient refusal. Restaging during treatment was planned every 12 weeks and objective responses were evaluated according to the Response Evaluation Criteria for Solid Tumors (RECIST) v. 1.0 [19]. All the responses and progressions were retrospectively evaluated by the investigators and no independent revision was performed.

Written informed consent for treatment, molecular analyses and data collection was obtained from each patient according to local Institution policies.

The Ethics Committee of Area Vasta Nord---Ovest approved the study.

\section{Mutational analysis Microdissection and DNA extraction}

Serial $5-\mu \mathrm{m}$ sections were taken from formalin fixed paraffin embedded (FFPE) tissues. The last section was stained with hematoxilin-eosin (H\&E), the tumor area was marked and the percentage of tumor cells was estimated by a pathologist. The tumor tissue was manually microdissected from one to three unstained sections previously submitted to xylene deparaffination, and was lysed overnight at $56^{\circ} \mathrm{C}$ in $180 \mu \mathrm{l}$ of ATL buffer and $20 \mu \mathrm{l}$ of proteinase K (QIAGEN, Hilden, Germany). DNA was purified using the spin column procedure (QIAamp minikit; QIAGEN) and finally reconstituted in $40 \mu \mathrm{l}$ of AE buffer. DNA content was measured with a Nanodrop-1000 spectrophotometer (Thermo Fisher Scientific Inc. Waltham, MA) and was kept at $4^{\circ} \mathrm{C}$ before use.

\section{Detection of EGFR mutations by PCR single-strand conformation polymorphism (SSCP) and direct DNA sequencing}

EGFR mutation analysis was performed by amplifying exons 18 to 21 as follows. $5 \mu \mathrm{L}$ of genomic DNA concentrated $20 \mathrm{ng} / \mu \mathrm{L}$ was amplified in a $25-\mu \mathrm{l}$ PCR mixture containing $12.5 \mu \mathrm{L}$ of HotStarTaq Master Mix Kit (QIAGEN) and $0.5 \mu \mathrm{L}$ of $20 \mathrm{uM}$ forward and reverse primers. All reactions were done in duplicate. The following PCR primers for EGFR exons 18-21 were used:

for exon 18, 5'(Fw)-CTCTGTGTTCTTGTCCCCCC-3' and $5^{\prime}(\mathrm{Rev})$-GCCTGTGCCAGGGACCTTAC-3'

(amplicon size, 166 bp); for exon 19, 5'(Fw)-CATGTGGCACCATCTCACA-3' and $5^{\prime}(\mathrm{Rev})$-CCACACAGCAAAGCAGAAAC-3'

(amplicon size, $179 \mathrm{bp}$ );

for exon 20, 5'(Fw)-CACACTGACGTGCCTCTCC-3' and $5^{\prime}(\operatorname{Rev})$-TATCTCCCCTCCCCGTATCT-3'

(amplicon size, $250 \mathrm{bp}$ );

for exon 21, 5'(Fw)-CCTCACAGCAGGGTCTTCTC-3' and 5'(Rev)-AATGCTGGCTGACCTAAAGC-3'

(amplicon size, 215 bp).

A mock control with no addition DNA was processed in parallel with each sample. Cycling conditions were as follows: initial denaturation $\left(95^{\circ} \mathrm{C}, 15 \mathrm{~min}\right)$, then 40 cycles of denaturation $\left(95^{\circ} \mathrm{C}\right.$ for $\left.30 \mathrm{sec}\right)$, annealing $\left(58^{\circ} \mathrm{C}\right.$ for $60 \mathrm{sec})$ and synthesis $\left(72^{\circ} \mathrm{C}\right.$ for $\left.60 \mathrm{sec}\right)$. All PCR products were visualized by electrophoresis on a $1.5 \%$ agarose gel stained with ethidium bromide. All PCR products were then diluted 1:1 with denaturing solution ( $1 \%$ xylene cyanol, 1\% bromophenol blue, $0.1 \mathrm{mM}$ EDTA and 99\% formamide), denatured at $95^{\circ} \mathrm{C}$ for $5 \mathrm{~min}$ and immediately placed on ice to prevent annealing of the single-strand products. SSCP was carried out on a GenePhor Electrophoresis Unit using GeneGel Excel 12.5/24 (12.5\% T, 2\% C) (GE Healthcare Biosciences AB, Uppsala, Sweden), according to the manufacturer's instructions. Electrophoresis $(600 \mathrm{~V}, 25 \mathrm{~mA}, 15 \mathrm{~W})$ was performed at $18^{\circ} \mathrm{C}$ for $100 \mathrm{~min}$. Gels were stained with the DNA Silver Staining Kit (GE Healthcare Biosciences AB), according to the manufacturer's instructions. Altered migrations patterns in two independent PCR-SSCP runs were indicative of DNA mutations. All PCR products were purified with QIAquick PCR Purification kit (QIAGEN) and labeled using the BigDye Terminator (version 3.1) Cycle Sequencing Kit (Applied Biosystems, Foster City, CA, USA) according to the manufacturer's protocol, and were followed by sequencing in an ABI 3130 Genetic Analyzer (Applied Biosystems). Both forward and reverse sequencing reactions were performed with the same PCR primers at $0.8 \mu \mathrm{mol} / \mathrm{L}$ in a final volume of $20 \mu \mathrm{L}$. The sequencing data were visualized using of Sequencing Analysis (Applied Biosystems), and were independently evaluated by two investigators.

\section{Detection of K-Ras mutation by pyrosequencing}

The K-Ras codons 12/13 mutational analysis was evaluated amplifying $5 \mu \mathrm{L}$ of genomic DNA concentrated $20 \mathrm{ng} / \mu \mathrm{L}$ by Anti-EGFR MoAb response ${ }^{\circ}$ (KRAS status) CE-IVD marked kits (DIATECH Pharmacogenetics, Italy) on Rotor-GeneTM 6000 (Corbett Research, Australia) following the manufacturer's instructions. The resulting PCR product was immobilized onto magnetic streptavidincoated beads via the biotin/streptavidin interaction. The bead/DNA complex was then washed and added to 1.65 pmol of pyrosequencing primer included in the same kit. 
The primed single-stranded DNA templates were then transferred to the microtitre plate-based PSQ HS 96 A Pyrosequencer (Biotage, Sweden), where real-time sequencing of the sequence surrounding codon 12/13 exon 2 of K-Ras was performed by using PyroMark Gold Q96 reagents (QIAGEN) on PyroMarkTM Q96 ID instrument (Biotage). The results were analyzed using PyroMark Q24 1.0.9 software, and were independently evaluated by two investigators.

\section{Statistical analysis}

EGFR and K-Ras mutations were correlated with clinical features such as smoking habits (never or former vs. current smokers) and brain metastases (yes vs. no) by means of the chi-square test.

The primary endpoints for correlative analyses were PFS times after first-line CT and salvage treatment with erlotinib. RR and OS were secondary endpoints.

PFS was calculated from the start of first-line CT or salvage erlotinib to the date of disease progression or death (whichever occurred first). OS was calculated from the start of first-line CT or salvage erlotinib to the date of death or last follow up visit. PFS and OS were estimated using the Kaplan-Meier method. Differences across curves were analyzed by log-rank test, while correlation with RR was estimated using the chi-square test. Statistical significance was set at $\mathrm{p}<0.05$ for a two-tailed test. Graphpad Prism 6 software was used for statistical analysis.

\section{Results}

\section{Patient characteristics}

A total of 103 women were identified and included in the descriptive analysis. Sixty-six patients, who received first-line platinum-based CT and whose clinical and molecular data were available, were included in the correlative analysis. The main characteristics are summarized in Table 1.

\section{EGFR and K-Ras mutations: correlation with clinical variables}

EGFR and K-Ras mutations were found in 30\% and 13\% of the cases, respectively (Table 2): in this series mutations in EGFR and K-Ras were mutually exclusive. EGFR mutations were exon 19 deletion (77\%), exon 21 L858R mutation (13\%) and exon 20 mutation (10\%). Among the K-Ras mutant cases, $77 \%$ and $23 \%$ had mutations in codons 12 and 13, respectively.

K-Ras mutations were significantly associated with smoking history: indeed, mutations were more frequent in current smokers compared to former or never smokers ( $28 \%$ vs. $8 \%$; $\mathrm{p}=0.024$ ). On the contrary, EGFR mutations occurred more frequently in never smokers, although the difference did not reach statistical significance (35\% vs. $19 \% ; \mathrm{p}=0.108)$.

In our series, there was no correlation between EGFR (mutant vs. wild-type: $13 \%$ vs. $15 \%$; $\mathrm{p}=1.000$ ) or K-Ras (mutant vs. wild-type: $0 \%$ vs. $18 \% ; \mathrm{p}=0.208$ ) status and the development of CNS metastasis during the clinical course of the disease.

At a median follow up of 46.7 months, $97 \%$ of the patients had progressed after first-line CT and 55\% had died.

\section{EGFR and K-Ras mutations: correlation with benefit from} first-line $C T$

Sixty-six patients were treated with first-line platinumcontaining CT. When the EGFR mutational status was considered, a significantly longer median PFS was observed among women with wild-type tumors than among women harboring mutant tumors (6.4 vs. 4.4 months, respectively; HR 0.597, 95\% CI 0.287-0.975; p=0.048) (Figure 1A). As regards K-Ras status, no significant difference was observed between wild-type and mutant patients in terms of median PFS (5.3 vs. 5.0 months, respectively; HR 1.041, 95\% CI 0.497-2.189; $\mathrm{p}=0.914$ ) (Figure 1B). When additional prognostic factors were analyzed (age, smoking habits, stage of disease, type of EGFR mutation), none was significantly associated with PFS (Table 3 ).

As regards RR, 26 (40\%) achieved an objective response, 20 (30\%) reported disease stabilization and 20 (30\%) progressed during CT. Neither EGFR nor K-Ras mutations significantly correlated with response to first-line CT: RR was $32 \%$ vs. $43 \%$ in EGFR mutant vs. EGFR wild-type tumors ( $\mathrm{p}=0.579)$, and $33 \%$ vs. $39 \%$ in K-Ras mutant vs. K-Ras wild-type tumors $(\mathrm{p}=1.000)$, respectively. No statistically significant differences in median OS were observed according to EGFR mutational status (wild-type vs. mutant: 29.5 vs. 26.2 months; HR 0.967, 95\% CI 0.473-1.974; $\mathrm{p}=0.926$ ) or K-Ras (wild-type vs. mutant: 26.1 vs. 26.8 months; HR 0.877 , 95\% CI 0.342-2.207; $\mathrm{p}=0.771)$.

\section{EGFR and K-Ras mutations: correlation with benefit from salvage erlotinib}

Thirty-nine (59\%) women received salvage treatment with erlotinib. At the time of the analysis, $74 \%$ progressed and median PFS for the entire population was 7.2 months. We observed a trend toward a higher benefit from erlotinib when administered in second line compared to third or fourth line (10.0 vs. 4.0 months, respectively; HR 0.587 , 95\% CI 0.206-1.145; $\mathrm{p}=0.132$ ): this difference was less evident when the analysis was restricted to EGFR mutant patients (12 and 3 patients for second-line and $\geq$ third-line treatment, respectively: 11.4 vs. 24.2 months). Unfortunately, five patients with EGFR mutant tumors experienced rapid worsening of general conditions after first-line 
Table 1 Patient demographic and clinical characteristics

\begin{tabular}{|c|c|c|c|c|c|c|}
\hline & \multicolumn{2}{|c|}{ Descriptive cohort $(n=103)$} & \multicolumn{2}{|c|}{ Correlative cohort $(n=66)$} & \multicolumn{2}{|c|}{ Anti-EGFR treated $(n=39)$} \\
\hline & n & $\%$ & n & $\%$ & $\mathrm{n}$ & $\%$ \\
\hline \multicolumn{7}{|l|}{ Age (years) } \\
\hline Median & 64 & & 60 & & 62 & \\
\hline Range & $38-88$ & & $38-81$ & & $38-77$ & \\
\hline \multicolumn{7}{|l|}{ Smoking history } \\
\hline Never smokers & 63 & 61 & 40 & 60 & 27 & 69 \\
\hline Former smokers & 8 & 8 & 5 & 8 & 4 & 10 \\
\hline Current smokers & 32 & 31 & 21 & 32 & 8 & 21 \\
\hline \multicolumn{7}{|l|}{ Stage } \\
\hline$\| \mathrm{B}$ & 30 & 29 & 17 & 26 & 11 & 28 \\
\hline IV & 73 & 71 & 49 & 74 & 28 & 72 \\
\hline \multicolumn{7}{|l|}{ Number of sites of metastases } \\
\hline 1 & 16 & 16 & 18 & 27 & 9 & 23 \\
\hline 2 & 25 & 24 & 26 & 39 & 13 & 33 \\
\hline$\geq 3$ & 62 & 60 & 22 & 34 & 17 & 44 \\
\hline \multicolumn{7}{|l|}{ CNS metastases } \\
\hline Yes & 14 & 14 & 12 & 18 & 7 & 18 \\
\hline No & 89 & 86 & 54 & 82 & 32 & 82 \\
\hline \multicolumn{7}{|l|}{ Previous surgery on primary } \\
\hline Yes & 46 & 45 & 20 & 30 & 14 & 36 \\
\hline No & 57 & 55 & 46 & 70 & 25 & 64 \\
\hline \multicolumn{7}{|l|}{ Previous (neo-)adjuvant CT } \\
\hline Yes & 9 & 9 & 5 & 8 & 4 & 10 \\
\hline No & 94 & 91 & 61 & 92 & 35 & 90 \\
\hline \multicolumn{7}{|l|}{ Previous adjuvant RT } \\
\hline Yes & 4 & 4 & 2 & 4 & 3 & 8 \\
\hline No & 99 & 96 & 63 & 96 & 36 & 92 \\
\hline \multicolumn{7}{|l|}{ First-line $C T$ regimen } \\
\hline Platinum + Paclitaxel & 10 & 10 & 10 & 15 & 5 & 13 \\
\hline Platinum + Gemcitabine & 39 & 39 & 39 & 59 & 21 & 54 \\
\hline Platinum + Pemetrexed & 13 & 13 & 13 & 20 & 6 & 15 \\
\hline Cisplatin + Vinorelbine & 2 & 2 & 2 & 3 & 1 & 3 \\
\hline Cisplatin-based triplet $C T$ & 2 & 2 & 2 & 3 & 2 & 5 \\
\hline Single-agent $C T^{*}$ & 26 & 26 & - & - & 4 & 10 \\
\hline Best supportive care only & 8 & 8 & - & - & - & - \\
\hline \multicolumn{7}{|l|}{ Anti-EGFR TKI treatment line } \\
\hline 2 & 28 & 27 & 24 & 36 & 27 & 69 \\
\hline$\geq 3$ & 12 & 12 & 9 & 14 & 12 & 31 \\
\hline
\end{tabular}

Abbreviations: TKls tyrosine-kinase inhibitors, ECOG Eastern Cooperative Oncology Group, CNS central nervous system, CT chemotherapy, $R T$ radiotherapy. *Single agent platinum, gemcitabine, vinorelbine, pemetrexed.

$\mathrm{CT}$ and died before having received any anti-EGFR TKI. None of the investigated clinical features was significantly associated with PFS in patient treated with erlotinib (Table 3).
EGFR mutations were significantly correlated with RR to salvage anti-EGFR TKI (mutant vs. wild-type: $60 \%$ vs. $12.5 \% ; \mathrm{p}=0.004$ ) and longer median PFS (mutant vs. wildtype: 11.4 vs. 4.5 months; HR 0.491, 95\% CI 0.216-0.936; 
Table 2 EGFR and K-Ras mutational status

\begin{tabular}{|c|c|c|c|c|c|c|}
\hline & \multicolumn{2}{|c|}{ Descriptive cohort $(n=103)$} & \multicolumn{2}{|c|}{ Correlative cohort $(n=66)$} & \multicolumn{2}{|c|}{ Anti-EGFR treated $(n=39)$} \\
\hline & $\mathrm{n}$ & $\%$ & $\mathrm{n}$ & $\%$ & $\mathrm{n}$ & $\%$ \\
\hline \multicolumn{7}{|l|}{ EGFR mutational status } \\
\hline Wild-type & 72 & 70 & 47 & 71 & 24 & 62 \\
\hline Mutant & 31 & 30 & 19 & 29 & 15 & 38 \\
\hline \multicolumn{7}{|l|}{ Sites of EGFR mutation } \\
\hline Exon 19 deletion & 24 & $77^{*}$ & 14 & $74^{*}$ & 12 & $80^{*}$ \\
\hline E746_A750del & 19 & $62^{*}$ & 10 & $54^{*}$ & 8 & $52^{*}$ \\
\hline E746_R748del & 1 & $3^{*}$ & 1 & $5^{*}$ & - & - \\
\hline E746_E749 > Y & 1 & $3^{*}$ & 1 & $5^{*}$ & 1 & $7^{*}$ \\
\hline L747_A750 > P & 1 & $3^{*}$ & 1 & $5^{*}$ & 1 & $7^{*}$ \\
\hline L747_T751del & 1 & $3^{*}$ & 1 & $5^{*}$ & 1 & $7^{*}$ \\
\hline S751_I759del & 1 & $3^{*}$ & - & - & 1 & $7^{*}$ \\
\hline Exon 20 mutation & 3 & $10^{*}$ & 2 & $10^{*}$ & - & - \\
\hline G796D & 2 & $7^{*}$ & 1 & $5^{*}$ & - & - \\
\hline A767_V769dup & 1 & $3^{*}$ & 1 & $5^{*}$ & - & - \\
\hline Exon 21 mutation & 4 & $13^{*}$ & 3 & $16^{*}$ & 3 & $20^{*}$ \\
\hline L858R & 4 & $13^{*}$ & 3 & $16^{*}$ & 3 & $20^{*}$ \\
\hline \multicolumn{7}{|l|}{ K-Ras mutational status } \\
\hline Wild-type & 76 & 73 & 46 & 70 & 30 & 77 \\
\hline Mutant & 13 & 13 & 9 & 14 & 4 & 10 \\
\hline Not evaluable & 14 & 14 & 11 & 16 & 5 & 13 \\
\hline \multicolumn{7}{|l|}{ Sites of K-Ras mutation } \\
\hline Codon 12 mutation & 10 & $77^{*}$ & 7 & $78^{*}$ & 4 & $100^{*}$ \\
\hline $\mathrm{G} 12 \mathrm{C}$ & 6 & $46^{*}$ & 4 & $44^{*}$ & 3 & $75^{*}$ \\
\hline G12D & 1 & $8^{*}$ & - & - & - & - \\
\hline G12V & 3 & $23^{*}$ & 3 & $34^{*}$ & 1 & $25^{*}$ \\
\hline Codon 13 mutation & 3 & $23^{*}$ & 2 & $22^{*}$ & - & - \\
\hline G13D & 3 & $23^{*}$ & 2 & $22^{*}$ & - & - \\
\hline
\end{tabular}

$\mathrm{p}=0.044$ ) (Figure 2A). There was a trend toward improved OS among mutant patients compared to wildtype ones (21.0 vs. 9.2 months, respectively; HR 0.560 , 95\% CI 0.231-1.156; $\mathrm{p}=0.131$ ).

PFS of K-Ras mutant women treated with salvage antiEGFR TKI was significantly reduced compared to that of wild-type ones receiving the same drug (median: 3.5 vs. 8.8 months; HR 0.284, 95\% CI 0.015-0.510; p=0.010) (Figure 2B). None of the patients harboring a K-Ras mutant tumor achieved an objective response to erlotinib compared with 10 out of 30 wild-type patients evaluable for the analysis (RR: $0 \%$ vs. 33\%; $p=0.296$ ): of these $10 \mathrm{~K}$-Ras wild-type patients, 8 harbored an EGFR mutant tumor. Of the two groups identified by K-Ras analysis, significantly shorter OS results were also reported in the mutant subset (median: 3.9 vs. 19.8 months in wildtype patients; HR 0.158, 95\% CI 0.001-0.075; p < 0.001).

\section{Discussion}

We retrospectively evaluated the outcomes of Caucasian women with lung adenocarcinoma, undergoing first-line platinum-based CT and subsequent salvage anti-EGFR TKI therapy, in relation to EGFR and K-Ras mutational status.

The clinical selection we applied (i.e. by gender and histology), together with the high percentage of never smokers in our series, is probably responsible for the high incidence of EGFR mutations (30\%) and the low frequency of K-Ras mutations (13\%) observed. As expected, K-Ras mutations were more frequent in current smokers, while a formally significant influence of smoking habits on the EGFR mutation rate was not detected: this was probably due to the small sample size and the potential confounding effect of other clinical selection criteria, such as gender and histology. In our series no patient had concomitant EGFR and K-Ras mutations. 

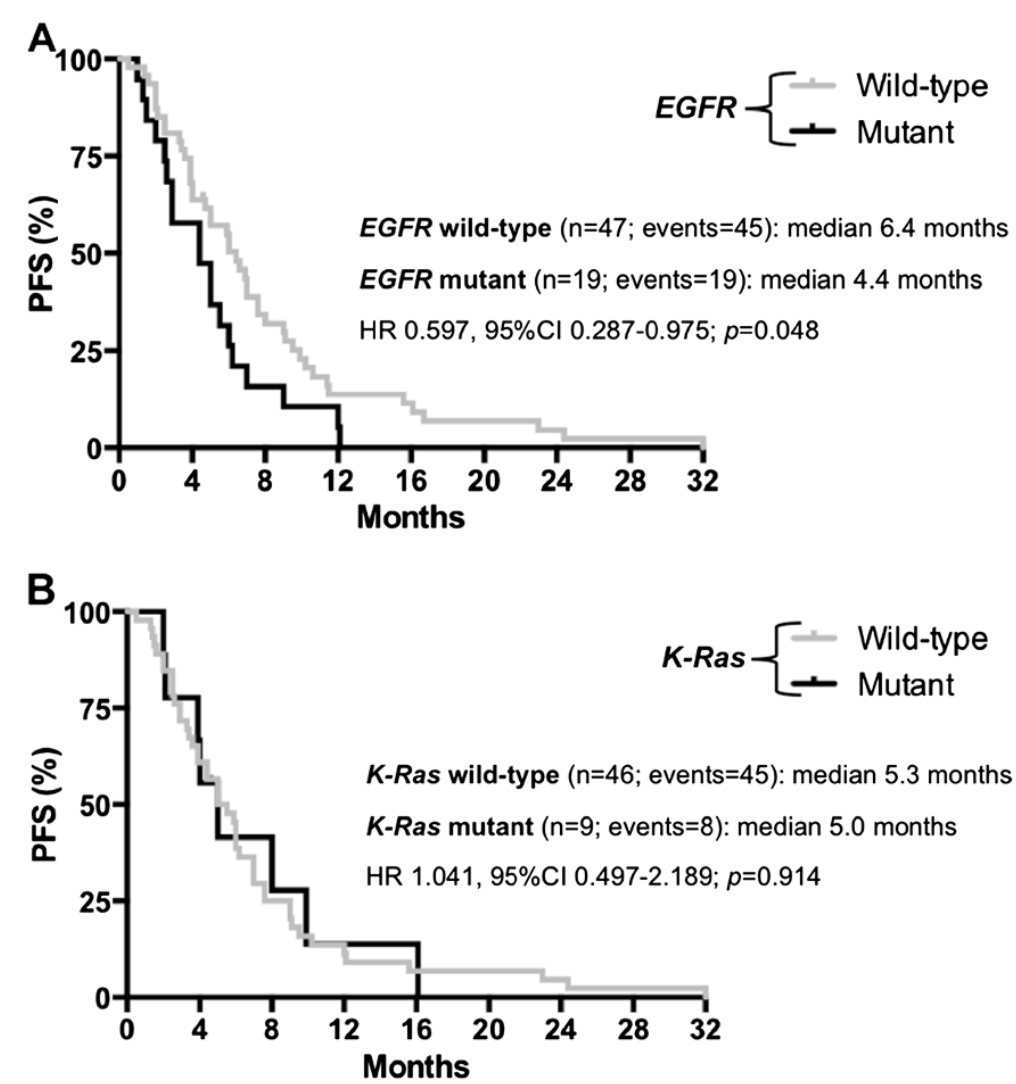

Figure 1 Progression---free survival (PFS) with CT according to molecular parameters. A. Progression-free survival (PFS) according to EGFR status among patients treated with first-line platinum-based combinations. B. Progression-free survival (PFS) according to K-Ras status among patients treated with first-line platinum-based combinations.

Table 3 Univariate analysis for PFS

\begin{tabular}{|c|c|c|c|c|}
\hline & \multicolumn{2}{|c|}{$\begin{array}{l}\text { Correlative cohort } \\
\qquad(n=66)\end{array}$} & \multicolumn{2}{|c|}{$\begin{array}{l}\text { Anti-EGFR treated } \\
(n=39)\end{array}$} \\
\hline & Median & $p$ & Median & $p$ \\
\hline Smoking history & & 0.246 & & 0.238 \\
\hline Never smokers & 5.0 & & 3.2 & \\
\hline Former smokers & 5.0 & & 5.6 & \\
\hline Current smokers & 7.0 & & 10.0 & \\
\hline Stage & & 0.130 & & 0.423 \\
\hline$\| \mathrm{B}$ & 7.6 & & 11.4 & \\
\hline IV & 5.0 & & 4.8 & \\
\hline Age & & 0.233 & & 0.894 \\
\hline$<70$ years & 5.5 & & 7.2 & \\
\hline$\geq 70$ years & 6.5 & & 5.0 & \\
\hline EGFR mutation* & & 0.373 & & 0.052 \\
\hline Exon 19 mutation & 4.4 & & 12.7 & \\
\hline Exon 20 mutation & 8.0 & & NA & \\
\hline Exon 21 mutation & 3.2 & & 1.4 & \\
\hline
\end{tabular}

Abbreviations: PFS progression-free survival, NA not applicable. *Analysis is restricted to EGFR mutant patients only.
Patients received first-line platinum-based CT according to clinical characteristics and physicians' choice. Retrospectively, the correlation between clinical parameters (RR, PFS and OS) and EGFR and K-Ras mutational status showed that women with EGFR mutant tumor achieved a marginally lower RR to first-line platinumbased combination ( $32 \%$ vs. $43 \%$; $\mathrm{p}=0.579)$ and a significantly shorter PFS (4.4 vs. 6.4 months; HR 0.597; $\mathrm{p}=0.048)$ compared to those with wild-type disease. There was no impact of the type of EGFR mutations on the PFS results and, as observed by previous reports, K-Ras mutations did not play a role in predicting the benefit from standard CT [16]. The effect of EGFR status on the efficacy of first-line platinum-based CT has been only rarely reported in the majority of studies and always with conflicting results [12]. The most recent and reliable data may be derived from trials of first-line CT vs. antiEGFR TKIs or CT plus a third targeted agent in molecularly unselected patients [8]. However, none of the reported analyses demonstrated a significant impact of EGFR mutational status on the benefit from first-line platinum-containing CT. Looking at the published or presented results, most trials suggest no role or, at best, 

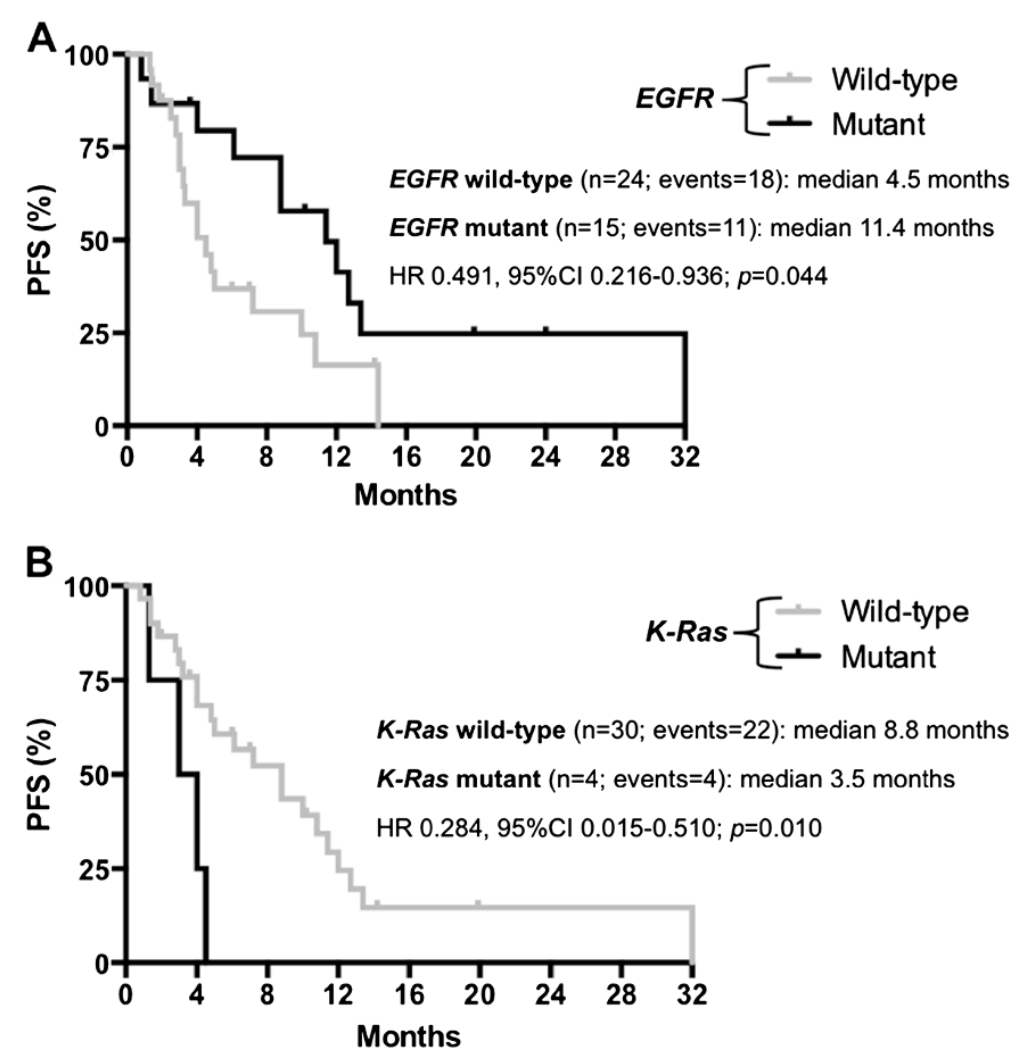

Figure 2 Progression---free survival (PFS) with anti---EGFR TKI according to molecular parameters. A. Progression-free survival (PFS) according to EGFR status among patients treated with anti-EGFR TKI. B. Progression-free survival (PFS) according to K-Ras status among patients treated with anti-EGFR TKI.

slightly better outcome for patients with EGFR mutant tumor when treated with first-line CT [8,12]. However, this remains an open issue and a definitive answer cannot be given since it would, in any case, suffer from several limitations (e.g., no gender selection, retrospective and unplanned nature of the analyses). Our series included only women with lung adenocarcinoma: female gender is an established good prognostic factor in NSCLC independently of disease stage, molecular status and treatment [20] and we cannot exclude a potential synergistic effect of gender and EGFR mutational status on the results we reported. Clinical enrichment in our study could also be the cause of the interesting median OS we observed (up to 29.5 months), not always reached in a population of unselected advanced NSCLC patients. However, although limited in size, our results further confirm the need of an upfront molecular characterization of all patients with lung adenocarcinoma before starting first-line treatment. In our series 5 patients with EGFR mutant disease died without receiving any anti-EGFR treatment, mainly because of a rapid worsening of performance status due to disease progression after first-line CT. Considering the huge amount of data supporting the superiority of antiEGFR TKIs compared with CT in these patients, every effort should be made to clarify the molecular profile of a lung adenocarcinoma before starting any treatment in everyday clinical practice.

Thirty-nine women received salvage erlotinib irrespectively of EGFR or K-Ras mutational status. EGFR mutations are a recognized predictive biomarker [11] and a regulatory requirement for the use of an anti-EGFR TKI as first-line approach [21]. Therefore, it is not surprising that, in our series, the benefit from erlotinib administered at progression was restricted to EGFR mutant cases both in terms of RR ( $\mathrm{p}=0.004)$ and PFS (HR 0.491; $\mathrm{p}=0.044)$. Moreover, women with EGFR mutant tumor treated with front-line CT and salvage anti-EGFR TKI showed a trend toward a better OS in comparison with those affected by EGFR wild-type tumor undergoing the same sequence (HR 0.560; $\mathrm{p}=0.131$ ). We might speculate that the disadvantage in PFS obtained with first-line CT in EGFR mutated women can be counterbalanced by the better results achieved with salvage anti-EGFR TKI. However, since a significant proportion of women with EGFR mutant tumors received no anti-EGFR TKI after first-line CT, once again we believe that these results stress the importance of a pre-specified sequence of approaches (upfront TKI followed by salvage $\mathrm{CT}$ ) in women harboring molecularly- 
addicted tumors in order to achieve the best outcome. The lack of any impact of the type of EGFR mutation on PFS could be due, at least in part, to the limited number of cases in our series.

In our clinically enriched population K-Ras mutations were not predictive of benefit from CT. As a matter of fact no difference in RR (33\% vs. $39 \%$ ) and PFS (5.0 vs. 5.3 months) was observed between patients with K-Ras mutant tumor and those with wild-type disease. The most recent report in a similar setting (i.e. EGFR wild-type patients treated with erlotinib after progression to first-line $\mathrm{CT}$ ) was the retrospective evaluation of K-Ras status in the TAILOR study [22]. In this randomized phase III trial K-Ras mutations were neither prognostic nor predictive of benefit from docetaxel and no significant interaction was demonstrated between K-Ras status and PFS or OS.

On the contrary, our results seem to suggest a putative negative predictive significance of K-Ras mutations for antiEGFR TKI activity. None of the patients with K-Ras mutant tumor achieved an objective response with salvage erlotinib and these patients experienced a significantly worse median PFS (HR 0.284; p = 0.010) and OS (HR 0.158; p < 0.001) compared with patients affected by wild-type NSCLC. Considering that the benefit from CT did not differ between the two groups and that K-Ras mutated women experienced not only a significantly shorter PFS on TKI but, in particular, a significantly reduced OS, we could argue that TKI administration in such a population could be potentially detrimental. However the limited number of patients in our series prevents us from drawing any definitive conclusion. Other larger data sets did not suggest any relevance of $\mathrm{K}$-Ras mutations in determining the benefit of CT [16], and taking into account the above mentioned conflicting results about the predictive role for anti-EGFR TKIs $[17,18]$, we do not believe that routine K-Ras sequencing should be considered in all patients with lung adenocarcinoma outside clinical and translational trials. This is particularly relevant when the tumor is not easily accessible for biologic sample collection and thus oncologists need to spare tissue for fundamental analyses, such as EGFR mutations and EML4-ALK translocation.

\section{Conclusions}

In our series of Caucasian women with advanced adenocarcinoma of the lung EGFR mutations seem to be associated with lower benefit from first-line platinum-based CT. If confirmed in larger, prospectively collected, datasets these results may help to shed light on the potential influence of gender on EGFR biology in NSCLC. We confirmed that the presence of an EGFR mutation strongly predicts the benefit of salvage treatment with erlotinib, stressing the role of this drug as first-line option in molecularly selected patients. The role of K-Ras mutations as biomarkers of resistance to anti-EGFR TKIs in NSCLC is still unclear and surely deserves further investigations.

\section{Abbreviations}

CNS: Central nervous system; CT: Chemotherapy; EGFR: Epidermal growth factor receptor (gene); EML4-ALK: echinoderm microtubule-associated protein-like 4 (EML4) - anaplastic lymphoma kinase (ALK) (genes); K-Ras: V-KI-RAS2 Kirsten rat sarcoma viral oncogene homolog (gene); NSCLC: Nonsmall cell lung cancer; OS: Overall survival; PFS: Progression-free survival; RECIST: Response evaluation criteria for solid tumors; RR: Response rate; TKI(s): Tyrosine-kinase inhibitor(s).

\section{Competing interests}

The authors declare that they have no competing interests.

\section{Authors' contributions}

$V R, L F, E V, C T, A C, A D, G C, A C, L G, S G, M C P$ and $E B$ were involved in patient management, data analysis, interpretation of the results and writing of the manuscript; LB, CL, ES and GF were involved in molecular analyses, interpretation of the results and writing of the manuscript; VR and EB developed the study design and supervised the drafting of the paper. All authors read and approved the final manuscript.

\section{Acknowledgements}

Supported by AIDACP Onlus (Associazione Italiana Donne anti Cancro Polmonare).

\section{Author details}

${ }^{1}$ U.O. Oncologia Medica, Ospedale San Luca, Lucca, Italy. ${ }^{2}$ U.O. Oncologia Medica 2 Universitaria, Azienda Ospedaliero-Universitaria Pisana, Pisa, Italy. ${ }^{3}$ U.O. Oncologia Medica, Ospedale Civile, Livorno, Italy.

${ }^{4}$ Dipartimento di Patologia Chirurgica, Medica, Molecolare e di Area Critica, Università di Pisa, Pisa, Italy. ${ }^{5}$ U.O. Pneumologia, Azienda Ospedaliero-Universitaria Pisana, Pisa, Italy. ${ }^{6}$ U.O. Oncologia Medica, Ospedale della Misericordia, Grosseto, Italy. 7U.O. Anatomia Patologica III, Azienda Ospedaliero-Universitaria Pisana, Pisa, Italy. ${ }^{8}$ U.O. Oncologia Medica, Ospedale di Carrara, Carrara, Italy.

Received: 6 September 2014 Accepted: 8 September 2014 Published online: 11 October 2014

\section{References}

1. Ciardiello F, Tortora G: EGFR antagonists in cancer treatment. N Engl J Med 2008, 358:1160-1174.

2. Capdevila J, Elez E, Macarulla T, Ramos FJ, Ruiz-Echarri M, Tabernero J: Anti-epidermal growth factor receptor monoclonal antibodies in cancer treatment. Cancer Treat Rev 2009, 35:354-363.

3. Harris TJ, McCormick F: The molecular pathology of cancer. Nat Rev Clin Oncol 2010, 7:251-265.

4. Schmoll HJ, Van Cutsem E, Stein A, Valentini V, Glimelius B, Haustermans K, van de Nordlinger B, Velde CJ, Balmana J, Regula J, Nagtegaal ID, Beets-Tan RG, Arnold D, Ciardiello F, Hoff P, Kerr D, Köhne CH, Labianca R, Price T, Scheithauer W, Sobrero A, Tabernero J, Aderka D, Barroso S, Bodoky G, Douillard JY, El Ghazaly H, Gallardo J, Garin A, Glynne-Jones R, Jordan K, Meshcheryakov A, Papamichail D, Pfeiffer P, Souglakos I, Turhal S, Cervantes A: ESMO ESMO Consensus Guidelines for management of patients with colon and rectal cancer. A personalized approach to clinical decision making. Ann Oncol 2012, 23:2479-2516.

5. Douillard JY, Oliner KS, Siena S, Tabernero J, Burkes R, Barugel M, Humblet Y, Bodoky G, Cunningham D, Jassem J, Rivera F, Kocákova I, Ruff P, Lasińska-Morawiec M, Smakal M, Canon JL, Rother M, Williams R, Rong A, Wiezorek J, Sidhu R, Patterson SD: Panitumumab-FOLFOX4 treatment and RAS mutations in colorectal cancer. N Engl J Med 2013, 369:1023-1034.

6. Siegel R, Naishadham D, Jemal A: Cancer statistics, 2013. CA Cancer J Clin 2013, 63:11-30.

7. Patel JD: Lung cancer in women. J Clin Oncol 2005, 14:3212-3218.

8. Cufer T, Ovcaricek T, O'Brien ME: Systemic therapy of advanced non-small cell lung cancer: major-developments of the last 5-years. Eur J Cancer 2013, 49:1216-1225. 
9. Shepherd FA, Rodrigues Pereira J, Ciuleanu T, Tan EH, Hirsh V, Thongprasert S, Campos D, Maoleekoonpiroj S, Smylie M, Martins R, van Kooten M, Dediu M, Findlay B, Tu D, Johnston D, Bezjak A, Clark G, Santabárbara P, Seymour L, National Cancer Institute of Canada Clinical Trials Group: Erlotinib in previously treated non-small-cell lung cancer. N Engl J Med 2005, 353:123-132.

10. Lynch TJ, Bell DW, Sordella R, Gurubhagavatula S, Okimoto RA, Brannigan BW, Harris PL, Haserlat SM, Supko JG, Haluska FG, Louis DN, Christiani DC, Settleman J, Haber DA: Activating mutations in the epidermal growth factor receptor underlying responsiveness of non-small-cell lung cancer to gefitinib. N Engl J Med 2004, 350:2129-2139.

11. Roengvoraphoj M, Tsongalis GJ, Dragnev KH, Rigas JR: Epidermal growth factor receptor tyrosine kinase inhibitors as initial therapy for non-small cell lung cancer: focus on epidermal growth factor receptor mutation testing and mutation-positive patients. Cancer Treat Rev 2013, 39:839-850.

12. Zhang Q, Dai HH, Dong HY, Sun CT, Yang Z, Han JQ: EGFR mutations and clinical outcomes of chemotherapy for advanced non-small cell lung cancer: A meta-analysis. Lung Cancer 2014, 85:339-345.

13. Kris MG, Johnson BE, Kwiatkowski DJ, lafrate AJ, Wistuba II, Aronson SL, Engelman JA, Shyr Y, Khuri FR, Rudin CM, Garon EB, Pao W, Schiller JH, Haura EB, Shirai K, Giaccone G, Berry LD, Kugler K, Minna JD, Bunn PA: Identification of driver mutations in tumor specimens from 1,000 patients with lung adenocarcinoma: The NCl's Lung Cancer Mutation Consortium (LCMC) [abstract]. J Clin Oncol 2011, 29, CRA7506.

14. Roberts PJ, Stinchcombe TE: KRAS mutation: should we test for it, and does it matter? J Clin Oncol 2013, 31:1112-1121.

15. Vasan N, Boyer JL, Herbst RS: A RAS renaissance: emerging targeted therapies for KRAS-mutated non-small cell lung cancer. Clin Cancer Res 2014, 20:3921-3930.

16. Loriot $Y$, Mordant $P$, Deutsch E, Olaussen KA, Soria JC: Are RAS mutations predictive markers of resistance to standard chemotherapy? Nat Rev Clin Oncol 2009, 6:528-534

17. Linardou H, Dahabreh IJ, Kanaloupiti D, Siannis F, Bafaloukos D, Kosmidis P, Papadimitriou CA, Murray S: Assessment of somatic k-RAS mutations as a mechanism associated with resistance to EGFR-targeted agents: a systematic review and meta-analysis of studies in advanced non-small-cell lung cancer and metastatic colorectal cancer. Lancet Oncol 2008, 9:962-972.

18. Mao C, Qiu LX, Liao RY, Du FB, Ding H, Yang WC, Li J, Chen Q: KRAS mutations and resistance to EGFR-TKls treatment in patients with non-small cell lung cancer: a meta-analysis of 22 studies. Lung Cancer 2010, 69:272-278.

19. Therasse P, Arbuck SG, Eisenhauer EA, Wanders J, Kaplan RS, Rubinstein L, Verweij J, Van Glabbeke M, van Oosterom AT, Christian MC, Gwyther SG: New guidelines to evaluate the response to treatment in solid tumours. European Organization for Research and Treatment of Cancer, National Cancer Institute of the United States, National Cancer Institute of Canada. J Natl Cancer Inst 2000, 92:205-216.

20. Bauml J, Mick R, Zhang Y, Watt CD, Vachani A, Aggarwal C, Evans T, Langer C: Determinants of survival in advanced non-small-cell lung cancer in the era of targeted therapies. Clin Lung Cancer 2013, 14:581-591.

21. European Medicines Agency: http://www.ema.europa.eu/ema/ [date last accessed: December 10, 2013].

22. Garassino M, Rulli E, Marabese M, Torri V, Longo F, Ganzinelli M, Farina G, Veronese S, Marsoni S, Broggini M: Prognostic and predictive role of KRAS mutations in patients with advanced non small cell lung cancer treated with docetaxel or erlotinib as second line treatment in the TAILOR trial [abstract]. Eur J Cancer 2013, 2:32.

doi:10.1186/s13046-014-0077-6

Cite this article as: Rotella et al.: EGFR and K-Ras mutations in women with lung adenocarcinoma: implications for treatment strategy definition. Journal of Experimental \& Clinical Cancer Research 2014 33:77.

\section{Submit your next manuscript to BioMed Central and take full advantage of:}

- Convenient online submission

- Thorough peer review

- No space constraints or color figure charges

- Immediate publication on acceptance

- Inclusion in PubMed, CAS, Scopus and Google Scholar

- Research which is freely available for redistribution

Submit your manuscript at www.biomedcentral.com/submit 